\title{
Unsere Kollegen von morgen
}

Klienten leiten wir Ergotherapeuten schon von Berufs wegen an: Wir geben ihnen Übungen mit nach Hause, zeigen, wie sie sich mit einer Hand anziehen können, oder erarbeiten eine Tagesstruktur mit ihnen. Wie sieht das aber mit der Anleitung von Schülern und Studenten aus? Darauf hat uns keiner vorbereitet. Wir erledigen diese Aufgabe häufig intuitiv und nebenbei.

Damit das praktische Lehren kein Bauchgefühl bleiben muss, fragte Milena Bick in ihrer Bachelorarbeit: Welche Schwierigkeiten haben Anleiter und was wünschen sie sich, um künftigen Berufskollegen eine qualitativ hochwertige praktische Ausbildung bieten zu können? Die Antworten, mit denen die Ergotherapiestudentin den Grundstein für eine Anleiterfortbildung legen möchte, lesen Sie ab Seite 36. Auch im praxisprofi beschäftigen wir uns mit Schülern und Studenten, deren praktische Berufsausbildung immer nur so gut sein kann wie der Beitrag, den erfahrene Kollegen in Praxis und Klinik leisten.

Der frische Wind, den Schüler und Studenten erfreulicherweise immer wieder mit sich bringen, weht derzeit auch durch die Redaktion von ergopraxis: Siebeneinhalb Jahre habe ich das Büro mit meiner Kollegin Maria Grupp geteilt. Jetzt ist sie in Elternzeit, und ich wünsche ihr alles erdenklich Gute für diese neue und spannende Herausforderung! Darum werden Sie bei uns künftig häufiger einen neuen Namen lesen: Bettina M. Heinrich. Ich freue mich sehr über ihre ergotherapeutische Unterstützung und dass sie unser Team bereichert.

Ihre
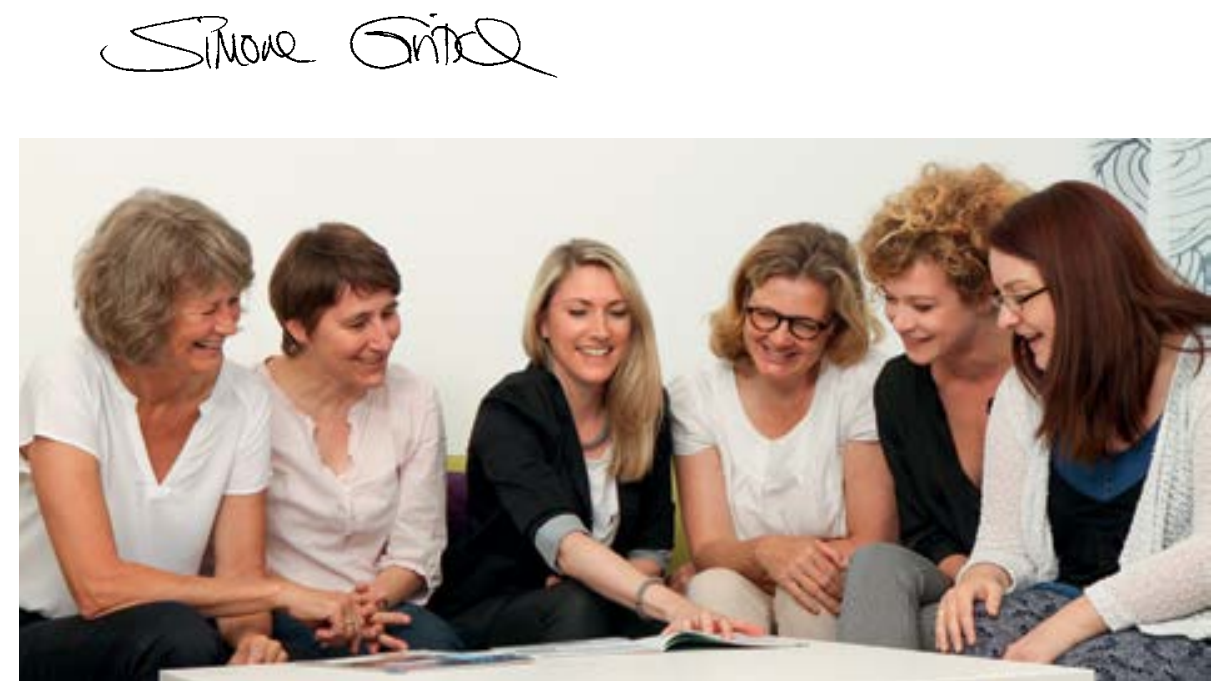

Das ist unser ergopraxis-Team! Von links: Annette Alkemade (Redaktionsassistenz), Elke Oldenburg (Redaktionsleitung), Simone Gritsch (Redaktion), Stephanie Eilmann (Marketing), Bettina M. Heinrich (Redaktion), Julia Belitz (Herstellung) 